to the inguinal ligament, plus remifentanil infusion $(0,02-$ $0,04 \mu \mathrm{g} / \mathrm{kg} / \mathrm{min}$ ) for sedation. The operation lasted 2 hours and the total administation of fentanyl was $2 \mu \mathrm{g} / \mathrm{kg}$ during the procedure.

Conclusions FBG nerve block plus local anesthesia can be an alternative for femoral endarterectomy.

\section{REGIONAL ANAESTHESIA SERVICE: POWER TO THE PATIENT}

A Ellison*, H Thompson, T Ashken. University College London Hospital, London, UK

10.1136/rapm-2021-ESRA. 188

Background and Aims Regional anaesthesia is an integral part of elective anaesthesia in modern hospitals and is almost obligatory now for certain orthopaedic and general surgical procedures. There is increasing requirements for efficiency on surgical lists in UK hospitals. Our regional service uses regional specialists and fellows to perform nerve blocks for patients before their surgical procedure and whilst the surgical list can concurrently progress. We aimed to discover if patient's satisfaction was also being met with this service.

Methods All patients who went through the regional anaesthesia service from 2017 to 2019 had a follow up SMS to their mobile phone after 48 hours. This just involved the patients clicking a link and answering 6 questions on their experience of the nerve block with a free text box for any comments on regional recommendations. Automated email alerts were sent if there was anything concerning.

Results As primary endpoints, 58\% stated that the pain block gave relief as expected and only $16 \%$ stating it was shorter pain relief than expected. $26 \%$ stated it lasted longer.

$59 \%$ stated they were extremely likely and $26 \%$ likely to recommend to family/friends.

A few of the negative comments involved pain on injection and long lasting motor block being uncomfortable and annoying.

Conclusions We have found that regional anaesthesia follow up is beneficial for patient safety, satisfaction and service

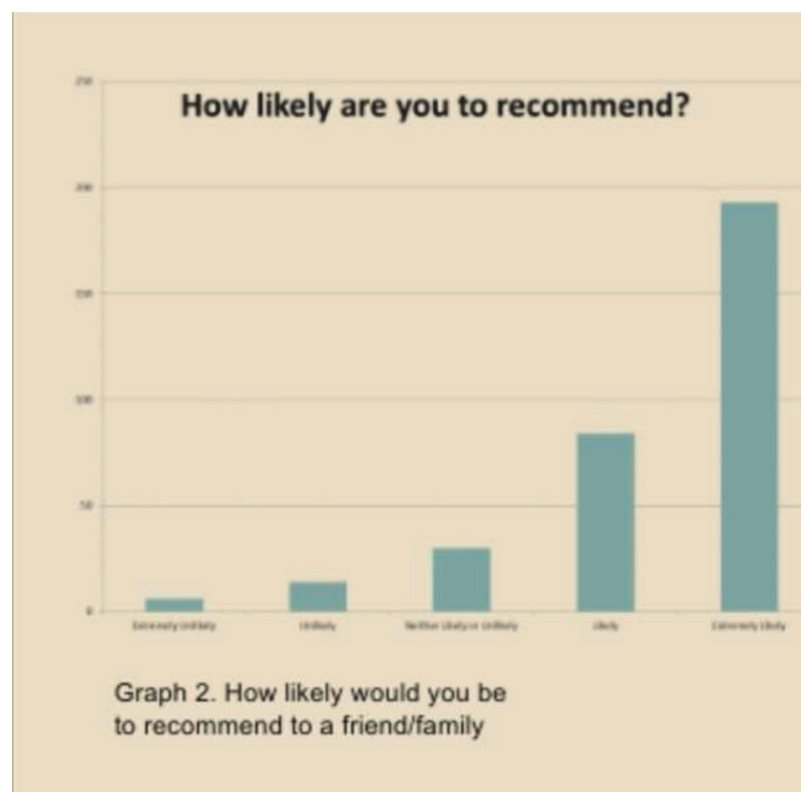

Abstract 188 Figure 1

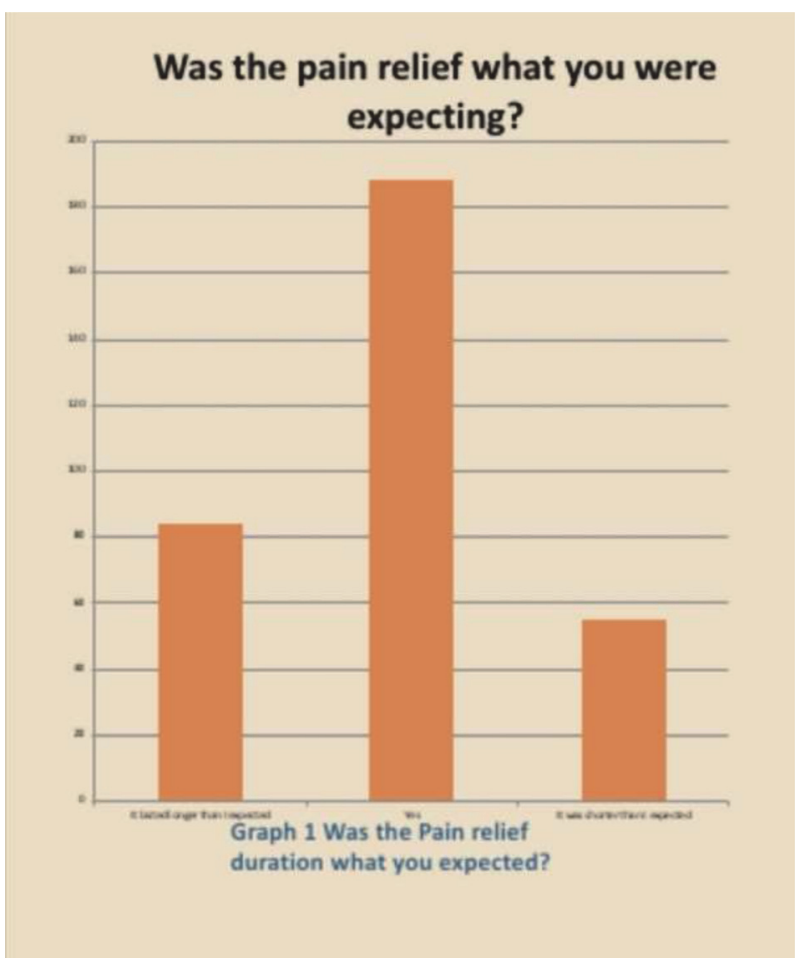

Abstract 188 Figure 2

improvement. There was overall a very positive response to regional anaesthesia and this has allowed us to make a business case for resources and funding.

\section{A CASE OF HORNER'S SYNDROME AFTER ULTRASSOM- GUIDED INTERSCALENE BRACHIAL PLEXUS BLOCK}

AM Schwalbert*, D de Pádua Resende Filho'. Hospital Independência, Porto Alegre, Brazil

\subsection{6/rapm-2021-ESRA. 189}

Background and Aims The brachial plexus innervates the upper limbs through roots from the cervical and thoracic nerves. Due to its anatomical location with proximity to other important nervous and vascular structures, which directly implies the occurrence of post-block complications. The purpose of this article is to review news evidence about the main complications of the interscalene brachial plexus block.

Methods Case report with bibliographic review of PUBMED with the descriptors 'interscalene block', without time limitation.

Results JFS patient, 61 years old, undergoes surgery to repair left rotator cuff injuries under interscalene brachial plexus block (Ropivacaine $0,5 \% 25 \mathrm{ml}$ e Clonidine $75 \mathrm{mcg}$ ) and sedation. Needle-guided ultrasound block Stimuplex ${ }^{\circledR}$ A50 (BBraun). The patient remained clinically stable throughout the procedure and was partially sedated to the recovery room.

When alert, the patient evolves with difficulties to communicate. On clinical examination, the patient presented hemodynamically stable with dysphonia and left eyelid ptosis. Kept under observation and after 24 hours the reported symptoms were no longer present.

Conclusions Horner's Syndrome (HS) is a set of signs and symptoms due to the blockade of the ipsilateral sympathetic pathway that innervates head, face and eye. Manifested with 